\title{
Programmable valve represents an efficient and safe tool in the treatment of idiopathic normal-pressure hydrocephalus patients
}

\author{
Válvula de pressão programável representa uma ferramenta eficaz e segura no \\ tratamento de pacientes com hidrocefalia de pressão normal idiopática \\ Matheus Fernandes de Oliveira ${ }^{1}$, Felippe Saad ${ }^{2}$, Rodolfo Casimiro Reis', José Marcus Rotta ${ }^{3}$, \\ Fernando Campos Gomes Pinto ${ }^{2}$
}

\begin{abstract}
Idiopathic normal pressure hydrocephalus (iNPH) is characterized by gait disturbance, dementia and /or urinary incontinence, dilation of the ventricular system and normal opening cerebrospinal fluid pressure. Shunt surgery is the standard treatment of iNHP. Diversions with programmable valves are recommended, once drainage pressure can be changed. However, well-defined protocols still lack guiding the steps to attain proper pressure for each patient. Methods: In our study, we reported the experience of shunting 24 patients with iNPH using Strata ${ }^{\circledR}$ (Medtronic) valve, following a protocol based on a positive Tap Test. Results: We observed clinical improvement in 20 patients and stability/ worsening in 4 patients. Complications occurred in five patients, including one death. The results display improvement, and complications occurred at a lower rate than reported in other studies. Conclusions: The Strata ${ }^{\circledR}$ valve used in the proposed protocol represents an efficient and safe tool in the treatment of iNPH.
\end{abstract}

Key words: hydrocephalus, normal pressure, cerebrospinal fluid shunts, treatment.

\section{RESUMO}

A hidrocefalia de pressão normal idiopática (iNPH) é caracterizada por alterações na marcha, demência e/ou incontinência urinária, além de dilatação dos ventrículos com pressão normal de abertura no líquido cefalorraquidiano. A cirurgia de derivação é o principal tratamento da iNHP. São recomendadas válvulas programáveis, pois a pressão de drenagem pode ser alterada. Embora as válvulas programáveis sejam utilizadas, não há protocolos para atingir a pressão adequada de cada paciente. Métodos: Neste estudo, relatamos nossa experiência com 24 pacientes com iNPH que usaram a válvula Strata ${ }^{\circledR}$ (Medtronic), seguindo protocolo baseado em um Tap test positivo. Resultados: Observamos melhora em 20 pacientes e estabilidade ou piora em 4. Ocorreram complicações em cinco pacientes, tendo um deles falecido. Houve importante melhora clínica, e as complicações ocorreram em taxa mais baixa do que as relatadas em outros estudos. Conclusões: A válvula Strata ${ }^{\circledR}$ utilizada no protocolo proposto representa uma ferramenta eficiente e segura no tratamento de iNPH.

Palavras-Chave: hidrocefalia de pressão normal, derivações do líquido cefalorraquidiano, tratamento.

Idiopathic normal pressure hydrocephalus (iNPH) is a condition characterized by gait disturbance, dementia and/or urinary incontinence without causative disorders, as well as dilation of ventricular system due to disturbance of cerebrospinal fluid (CSF) circulation with normal CSF pressure and no secondary cause $\mathrm{e}^{1-3}$. It is a differential diagnosis for most of the dementia syndromes and occurs mainly in elderly populations ${ }^{4}$.

The known incidence is approximately 6 per 100,000 and it has a prevalence of 22 per 100,000 for suspected iNPH.
There are associations with hypertension, cerebrovascular and Alzheimer diseases ${ }^{1-3}$.

The clinical evolution of iNPH is not clear ${ }^{5}$. Without surgery, most iNPH patients present early clinical deterioration. A small number of patients might improve without shunting; however, the extent of improvement is not clear 3 .

Ventricular CSF shunting is the main treatment in the management of iNPH and its results in reducing the caregiver's burden when caring for iNPH patients are well-established ${ }^{6}$.

\footnotetext{
'Neurosurgery Residency Program, Department of Neurosurgery, Hospital do Servidor Público Estadual de São Paulo, São Paulo SP, Brazil;

${ }^{2}$ Post Graduation Program, Hospital das Clínicas, Faculty of Medicine, University of São Paulo (USP), São Paulo SP, Brazil.

${ }^{3}$ Department of Neurosurgery, Hospital do Servidor Público Estadual de São Paulo, São Paulo SP, Brazil;

Correspondence: Matheus Fernandes de Oliveira; Avenida Pedro de Toledo 1800; 04039-004 São Paulo SP - Brasil; E-mail: mafernoliv@yahoo.com.br

Conflict of interest: There is no conflict of interest to declare.

Received 25 July 2012; Received in final form 24 October 2012; Accepted 31 October 2012.
} 
Shunting with programmable valves is indicated, as the drainage pressure can be adjusted. Theoretically, after shunting, there is less pressure in ventricle walls, determining better perfusion and potentially re-establishing functions. Hemodynamic evaluations have already shown a higher cerebral blood flow in patients with $\mathrm{iNPH}^{7,8}$. Another theoretical statement is the linkage between perfusion and function, but also depending in increasing complexity of the neural network after shunting ${ }^{9-11}$.

However, the surgical approach to iNPH may result in complications, especially mechanical malfunction, infections and overdrainage. When the valve pressure is too low, there is excessive drainage, creating negative pressure inside the skull, sometimes causing rupture of veins in the subdural space, creating nontraumatic subdural hematomas or hygromas ${ }^{12-15}$.

This study aimed to describe the experience with patients with iNPH at the stages of admission, diagnosis, surgery (programmable valve Strata ${ }^{\circledR}$ - Medtronic) and postoperative follow-up and to propose a routine of follow-up and a standard protocol for valve adjustment.

\section{METHODS}

We prospectively selected patients with a diagnosis of iNPH from January 2010 to January 2012 in a Brazilian tertiary hospital. They were users of this medical facility screened

\section{Patient with Clinical + Radiological findings}

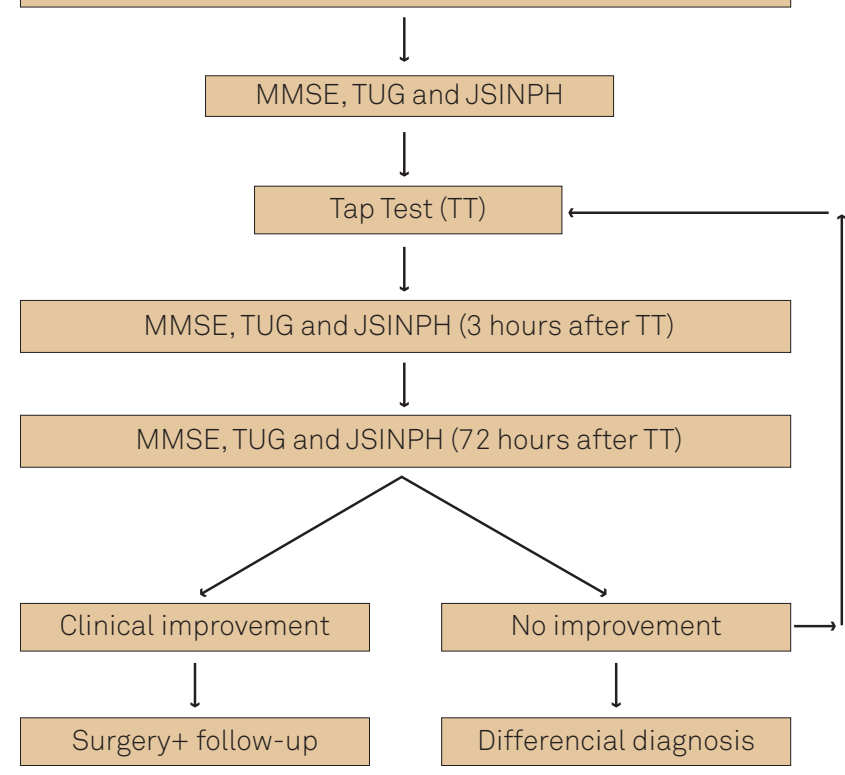

MMSE: Mini-Mental State Examination; TUG: Time Up and Go; JSINPH: Japanese Scale for Idiopathic Normal Pressure Hydrocephalus; TT: Tap Test.

Fig 1. Protocol design. The scheme displays the protocol consisting in patients selection and undergoing the tests MMSE, TUG and JSINPH before and after TT, in order to determine the suitability of diversion surgery. in the hospital wards and forwarded by neurologists, geriatricians and other physicians. These patients underwent elective ventriculoperitoneal shunt with Strata ${ }^{\circledR}$ programmable valve system. It is an interventional, non-controlled, study with prospective features. The project was approved by the Research and Ethics Committee.

The accepted diagnostic criteria were: clinical syndrome consistent with Adams-Hakim (gait apraxia, urinary incontinence and dementia) associated with ventricular dilatation documented by cranial computed tomography (CT) and magnetic resonance imaging (MRI) scans. Inclusion criteria: diagnosis of iNPH, absence of malignant disease and well-controlled clinical comorbidities (hypertension, diabetes mellitus, hormonal disorders, etc.). Exclusion criteria: diagnosis of secondary NPH, inability to walk, malignancy and uncontrolled clinical comorbidities.

To select the patients, we considered typical clinical settings, such as urinary incontinence, gait disturbance and dementia, as well as compatible image studies associated to clinical response to Tap Test (TT). All patients underwent clinical evaluation, which consists of the Mini-Mental State Examination (MMSE) ${ }^{16}$ and Time Up and Go (TUG) ${ }^{17}$ tests and the application of Japanese Scale for Idiopathic Normal Pressure Hydrocephalus $(\text { JSINPH })^{2}$ in three stages: prior to the TT, 3 hours after the TT and 72 hours after the TT (Figs 1 and 2).

All patients were submitted to imaging studies (CT scan and MRI of the skull with CSF flow study) in order to screen for secondary causes of hydrocephalus. The standard measure used to determine the concept of hydrocephalus was the Evans Ratio (ER), which consists in dividing the distance between frontal horns of lateral ventricles to maximal biparietal diameter. An ER value $>0.3$ is compatible with ventriculomegaly.

\section{JSINPH}

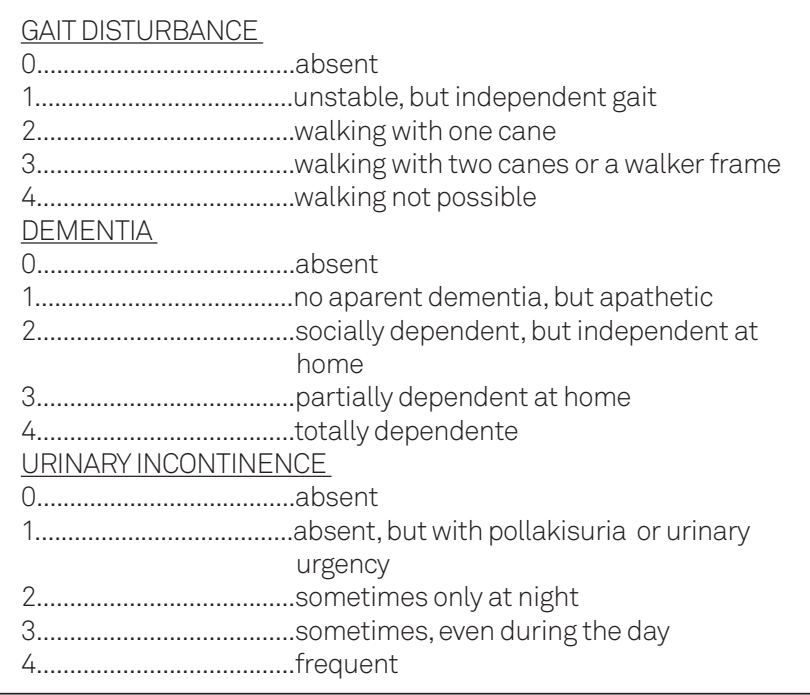

Fig 2. Japanese Scale for Idiopathic Normal Pressure Hydrocephalus (JSINPH) is a recognized tool to evaluate and grade the three main symptoms in Idiopathic Normal Pressure Hydrocephalus (iNPH). 
Once the diagnosis of hydrocephalus is established and secondary causes are excluded, the testing phase was carried out to verify whether the diversion procedure with programmable valves would be adequate.

Each patient was submitted to a protocol, which consists of two steps:

- Step 1 - (a) performance of the MMSE; (b) Time Up and Go; (c) application of the Japanese Scale for Idiopathic Normal Pressure Hydrocephalus; (d) lumbar puncture with drainage of $40-50 \mathrm{~mL}$ of CSF and manometry (TT).

- $\quad$ Step 2 - three hours after the puncture, steps (a), (b) and (c) were repeated.

According to the results, patients were taken back to the clinic or submitted to peritoneal shunt with Strata ${ }^{\circledR}$ adjustable valve (Medtronic).

The MMSE ${ }^{16}$ is a standard test introduced by Folstein in order to evaluate the general patterns of dementia disorders. The Time Up and $\mathrm{Go}^{17}$ is a test that consists of measuring the time it takes for an individual to rise from a chair, walk three meters and sit back, assessing gait independence. The cutoff is approximately 12 seconds, although some authors diverge. Thus, patients able to perform the route in less than 12 seconds are considered independent with respect to gait, while those who take longer conceptually have a gait dysfunction. It should be noted that patients with orthopedic and neurological sequelae automatically take more time to complete the route. The Japanese grading scale for $\mathrm{iNPH}^{2}$ is a tool to access the patients' clinical background. It measures the three main symptoms in different degrees of presentation, and can be easily performed in the preoperative period and as an evaluation questionnaire and in the follow-up of the patients.

The $\mathrm{TT}^{1-3,18}$ is a recognized test that consists in the removal of varying amounts of CSF (40 to $50 \mathrm{~mL}$ ) by lumbar puncture, after which the patient with suspected iNPH has hypothetically symptom improvement. It is believed that the removal of the excessive cerebrospinal fluid CSF by puncturing allows a transient improvement in clinical pattern. Usually, the element that responds better to the TT is gait, followed by urinary incontinence. As there is a learning bias in the application of MMSE, we considered an improvement after TT in patients with any better scores in TUG and/or JSINPH. The subjective opinion was also considered, added to TUG and/or JSINPH.

Ventricular peritoneal shunt surgery was indicated for patients with improvement in at least one of the classic triad of symptoms, in any degree. As there is a learning bias for the MMSE, we decided to associate their improved score to an improvement in some other parameter (urinary incontinence or gait). The subjective improvement reported by patients was also considered, but as it was difficult to measure it and due to the low degree of reliability of some reports, even because of dementia, we chose to always associate an objective parameter.

In this manner, patients with indication for surgery underwent ventricular peritoneal shunt through strict technique, with the right frontal trepanation point of Kocher. The valve applied in the study was the Strata ${ }^{\circledR}$ (Medtronic), which is an externally adjustable magnetic radiopaque with anti-siphoning valve programmed to one of five performance level settings, from 0.5 to 2.5 , with 0.5 increments, with each level setting being correspondent to a drainage pressure ${ }^{19}$ (Table 1 ). The Strata ${ }^{\circledR}$ valve (Medtronic) was then adjusted to 2.5 (140 $\mathrm{mmHg}$ ), and the patient was discharged with monthly follow-up in the first three months and then quartlely follow-up. Our final follow-up time was one year.

In this protocol, we proposed the adjustment of the valve according to symptoms, assessed with the JSINPH, Time Up and Go, MMSE and pattern of hydrocephalus. The valve level should start in 2.5 and be adjusted on a quarterly basis, with reductions of 0.5 per occasion towards the best clinical outcome, avoiding complications and symptoms of overdrainage. The objective was to achieve the lowest performance level in order to reduce the hydrocephalus and its symptoms, and the limits were the lowest level (0.5) or a level which caused new symptomatology, suggesting overdrainage (headache, dizziness, slit ventricle syndrome and signs of dural detachment).

The team involved in the execution of the preoperative tasks consists of two neurosurgeons guided by a senior neurosurgeon. The evaluations of each patient before and after TT were performed by the same professional. The operative and follow-up tasks were conducted by the same team with the help of two more neurosurgeons.

\section{Statistics}

In this study, numerical data are presented as mean \pm standard deviation (SD) or median with range when appropriate. Categorical data are presented as percentages. When comparing groups, the level of significance is considered when $\mathrm{p}<0.05$. To determine the distribution of our data, the Kolmogorov-Smirnov test was used. As all our numerical variables were parametric, Student's

Table 1. Correspondence between level setting and drainage pressure in Strata ${ }^{\circledR}$ valve.

\begin{tabular}{lc} 
Level Setting & Drainage Pressure \\
\hline 0.5 & $20 \mathrm{mmHg}$ \\
1.0 & $40 \mathrm{mmHg}$ \\
1.5 & $80 \mathrm{mmHg}$ \\
2.0 & $110 \mathrm{mmHg}$ \\
2.5 & $140 \mathrm{mmHg}$ \\
\hline
\end{tabular}


$t$-test was used in the statistical evaluation for paired and unpaired groups, when appropriate. For categorical variables evaluation, the Chi-Square and Mc'Nemar tests were used, when respectively appropriate.

\section{RESULTS}

\section{Characterization of patients}

A total of 32 patients were selected for the protocol. Even with the clinical and imaging screening performed, 8 patients were unsuitable for the protocol. In one, the MRI revealed aqueduct stenosis. In the other seven, the Tap Tests were negative in two occasions and, so, they were excluded (Table 2).

Thus, 24 patients (11 females and 13 males) underwent ventriculoperitoneal shunt with programmable Strata ${ }^{\circledR}$ (Medtronic) valve. The mean age was 77.1 with SD of 5.99. The mean age of the female group was 76.36 with SD of 7.22. The mean age in the male group was 72.57 with SD of 4.91. The two groups were statistically equal ( $p>0.05)$. As our hospital is reference for a population of approximately 2 million inhabitants, the incidence found was 1.2 per 100,000 .

All 24 patients presented with some sort of symptoms from the Hakim's triad. As expected, the dementia symptoms were presented for more time, for an average of 35 months previously to surgery. Gait apraxia was presented for a mean of 25 months, and urinary incontinence for 22 months.

The diagnostic and preoperative mean Evan's ratio was 0.37 with SD of 0.03 , with no statistically difference between females and males. The preoperative MMSE mean was 19 before TT and 21 after TT, with statistical difference $(p=0.01)$. The mean preoperative Japanese Scale was 6 before TT and 5 after TT, with statistical difference $(\mathrm{p}=0.001)$. Mean preoperative TUG was 41 seconds before and 36.41 seconds after TT, with statistical difference $(\mathrm{p}=0.003)$. The CSF mean pressure was $152 \mathrm{mmHg}$ before and $29 \mathrm{mmHg}$ after the TT.

The initial valve status performance was 2.5 until follow-up. The patients were routinely discharged in the second postoperative day and were followed-up monthly in the first three months and, then, quartely. The parameters used for adjustment of the valve were radiological findings and clinical symptoms. Our time of follow-up was one year.

\section{Outcome}

After one year of follow-up, the average number of adjustments in valve pressure was 3.125, varying from a single adjustment in four patients to six adjustments in other four patients (Table 2). The final performance mean setting adjustment was 1.5. All the patients had their settings between 1 and 2 .

The objective clinical and radiological results were astounding. The mean MMSE changed from 19 to 21 ( $p=0.03)$. JSINPH changed from 6 to 4.63 ( $p=0.016)$. TUG, which before surgery was 41 seconds, became 35.77 seconds in the follow-up $(\mathrm{p}=0.01)$. The Evans Ratio in CT scans changed from 0.37 to 0.33 ( $\mathrm{p}=0.0001)$, as illustrated in Fig 3.

Four patients (three males e one female) did not show clinical improvement. One presented worsening of gait and dementia instead of radiological improvement (Evans changed from 0.45 to 0.38 ); other patient presented stroke during the course of the follow-up, resulting in confusional state and hemiparesis; another one developed subdural hematoma followed by subdural empyema, resulting in septic shock and death; the only female referred worsening of gait instead of surgery.

The radiological results revealed that in 23 patients the Evans ratio decreased after shunting. Only one male patient (subject 2) presented increase in Evans ratio (from 0.36 to 0.40), instead of clinical improvement.

\section{Complications}

There were eight complications in five patients (three males and two females). We consider major complications those requiring surgical correction, including subdural hematomas and empyemas, permanent shunt obstruction and shunt infection. We consider minor complications those in which the adjustment of pressure and clinical measures were sufficient and effective for the control, including wound dehiscence, slit ventricle syndrome, transient shunt obstruction and resetting after MRI procedures ${ }^{20,21}$ (Table 2).

In the follow-up, malfunctioning of the valve forced the valve revision in two patients. One patient presented wound dehiscence and valve exposure after six months of the surgery, and it was necessary to remove the valve. There was no significant difference in complications rate between males and females $(\mathrm{p}<0.01)$.

Subdural collections occurred in four patients. One of them developed subdural collection after ongoingMRI examination and havingthevalvepressure reset (Fig 4). Initially, all collections were subdural hematomas, two managed conservatively with valve adjustment and two with surgical treatment. The decision was made considering the patient clinical presentation, location and volume of the hematoma. The asymptomatic/oligosymptomatic patients had their valves adjusted and were followed with resolution of the hematomas. The symptomatic patients or those with large collections were managed aggressively with surgical drainage ${ }^{22}$.

The management of subdural hematomas with valve adjustment consisted of resetting the level to 2.5 and weekly follow-up until recovery from symptoms and absorption of the hematoma. After that, the patient began again the quarterly adjustment towards the best level without new complications.

Fortunately, shunt infections did not occur in our sample. However, in one case, the subdural hematoma recurred after the first drainage, and after the second drainage there was 


\begin{tabular}{|c|c|c|c|c|c|c|c|c|c|c|c|c|c|c|c|c|}
\hline \multirow{2}{*}{ 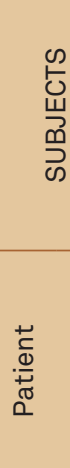 } & \multirow{2}{*}{ 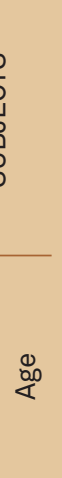 } & \multicolumn{3}{|c|}{ 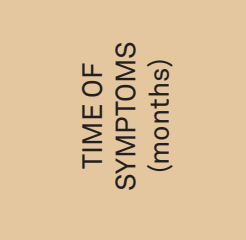 } & \multicolumn{4}{|c|}{ 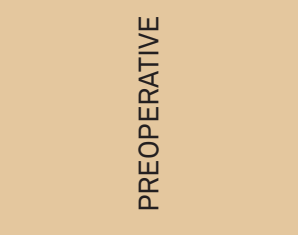 } & \multicolumn{8}{|c|}{ 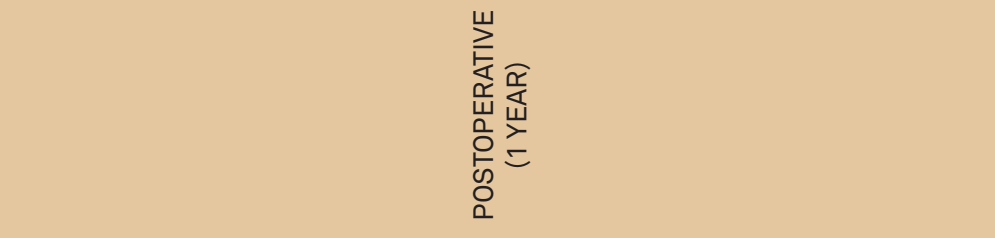 } \\
\hline & & $\stackrel{+\pi}{\widetilde{\sigma}}$ & 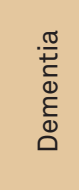 & 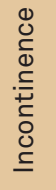 & $\underset{\text { W }}{\stackrel{\infty}{\mathbf{L}}}$ & $\sum_{\Sigma}^{\text {W }}$ & 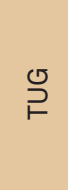 & $\begin{array}{l}\frac{I}{D} \\
\frac{Z}{\mathcal{D}} \\
\stackrel{S}{\supset}\end{array}$ & $\underset{W}{\stackrel{\infty}{Z}}$ & $\sum_{\Sigma}^{W}$ & 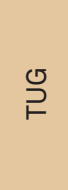 & $\begin{array}{l}\frac{T}{0} \\
\frac{D}{Z} \\
\end{array}$ & 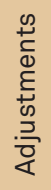 & 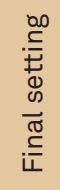 & $\begin{array}{l}\stackrel{ }{.0} \\
\frac{\pi}{0} \\
.0 \\
0 \\
\frac{0}{\varepsilon} \\
0 \\
0\end{array}$ & $\begin{array}{l}z \\
\frac{z}{z} \\
\frac{0}{0} \\
0\end{array}$ \\
\hline 1 & 62 & 6 & 6 & 6 & 0.36 & 29 & 9 & 5 & 0.32 & 29 & 8 & 4 & 3 & 1.5 & & SATISFIED \\
\hline 2 & 79 & 36 & 36 & 36 & 0.36 & 28 & 13 & 4 & 0.4 & 26 & 14 & 3 & 6 & 1 & & SATISFIED \\
\hline 3 & 82 & 48 & 48 & 48 & 0.3 & 25 & 17 & 6 & 0.28 & 25 & 14 & 5 & 2 & 1.5 & & SATISFIED \\
\hline 4 & 80 & 24 & 18 & 18 & 0.36 & 29 & 20 & 4 & 0.35 & 29 & 19 & 3 & 5 & 1 & & SATISFIED \\
\hline 5 & 88 & 6 & 72 & 6 & 0.36 & 18 & 22 & 8 & 0.3 & 22 & 16 & 7 & 2 & 1 & & SATISFIED \\
\hline 6 & 70 & 10 & 24 & 12 & 0.37 & 19 & 24 & 5 & 0.32 & 21 & 29 & 3 & 1 & 2 & & SATISFIED \\
\hline 7 & 77 & 6 & 6 & 6 & 0.38 & 15 & 25 & 3 & 0.35 & 17 & 23 & 2 & 1 & 2 & & SATISFIED \\
\hline 8 & 70 & 72 & 96 & 60 & 0.4 & 20 & 26 & 4 & 0.36 & 21 & 22 & 3 & 2 & 1.5 & & SATISFIED \\
\hline 9 & 83 & 12 & 12 & 12 & 0.47 & 24 & 26 & 4 & 0.34 & 18 & 56 & 5 & 6 & 2 & $\begin{array}{l}\text { malfunction and subdural } \\
\text { hematoma }\end{array}$ & UNSATISFIED \\
\hline 10 & 69 & 12 & 12 & 12 & 0.41 & 25 & 27 & 4 & 0.38 & 26 & 20 & 3 & 2 & 1.5 & & SATISFIED \\
\hline 11 & 82 & 72 & 72 & 24 & 0.42 & 18 & 29 & 5 & 0.38 & 19 & 26 & 4 & 6 & 1.5 & $\begin{array}{c}\text { malfunction and subdural } \\
\text { hematoma }\end{array}$ & SATISFIED \\
\hline 12 & 73 & 12 & 36 & 12 & 0.37 & 21 & 37 & 8 & 0.34 & 21 & 50 & 7 & 6 & 1 & & UNSATISFIED \\
\hline 13 & 73 & 12 & 12 & 12 & 0.4 & 21 & 38 & 8 & 0.35 & 20 & 49 & 7 & 5 & 1 & & UNSATISFIED \\
\hline 14 & 82 & 72 & 72 & 36 & 0.41 & 9 & 40 & 4 & 0.35 & 14 & 38 & 3 & 5 & 2.5 & $\begin{array}{c}\text { subdutal hematoma and } \\
\text { empyema }\end{array}$ & UNSATISFIED \\
\hline 15 & 84 & 12 & 12 & 18 & 0.4 & 15 & 41 & 6 & 0.35 & 20 & 20 & 2 & 4 & 1.5 & subdural hematoma & SATISFIED \\
\hline 16 & 75 & 18 & 18 & 24 & 0.35 & 13 & 45 & 6 & 0.31 & 18 & 20 & 1 & 3 & 1 & & SATISFIED \\
\hline 17 & 84 & 12 & 24 & 18 & 0.37 & 18 & 50 & 3 & 0.32 & 21 & 40 & 2 & 1 & 2 & & SATISFIED \\
\hline 18 & 73 & 12 & 12 & 12 & 0.35 & 20 & 57 & 5 & 0.34 & 23 & 45 & 3 & 2 & 1.5 & & SATISFIED \\
\hline 19 & 77 & 12 & 12 & 36 & 0.37 & 24 & 60 & 9 & 0.34 & 26 & 48 & 5 & 2 & 1.5 & & SATISFIED \\
\hline 20 & 78 & 36 & 36 & 36 & 0.36 & 21 & 66 & 10 & 0.32 & 23 & 40 & 8 & 2 & 1.5 & & SATISFIED \\
\hline 21 & 82 & 30 & 30 & 30 & 0.32 & 18 & 70 & 8 & 0.3 & 16 & 55 & 7 & 3 & 1 & & SATISFIED \\
\hline 22 & 75 & 24 & 24 & 24 & 0.38 & 11 & 164 & 0 & 0.33 & 11 & 135 & 7 & 2 & 1.5 & & SATISFIED \\
\hline 23 & 74 & 60 & 72 & 36 & 0.41 & 18 & 67 & 4 & 0.37 & 22 & 52 & 2 & 3 & 2 & & SATISFIED \\
\hline 24 & 79 & 6 & 96 & 12 & 0.34 & 14 & 80 & 12 & 0.31 & 19 & 58 & 11 & 1 & 2 & valve exposure & SATISFIED \\
\hline
\end{tabular}

MMSE: Mini-Mental State Examination; TUG: Time Up and Go; JSINPH: Japanese Scale for Idiopathic Normal Pressure Hydrocephalus.

progression to subdural empyema. This patient died from septic shock.

\section{Subjective opinion}

After one year of the surgery, we asked the families of the patients and the patients themselves about the subjective outcome, in other words, if the family was satisfied or not and if there was improvement in the caregiver's burden. Of the 24 families/patients, 20 referred some degree of subjective improvement. Four families/ patients referred no improvement, with stability of the clinical profile in three cases (including the patient who 

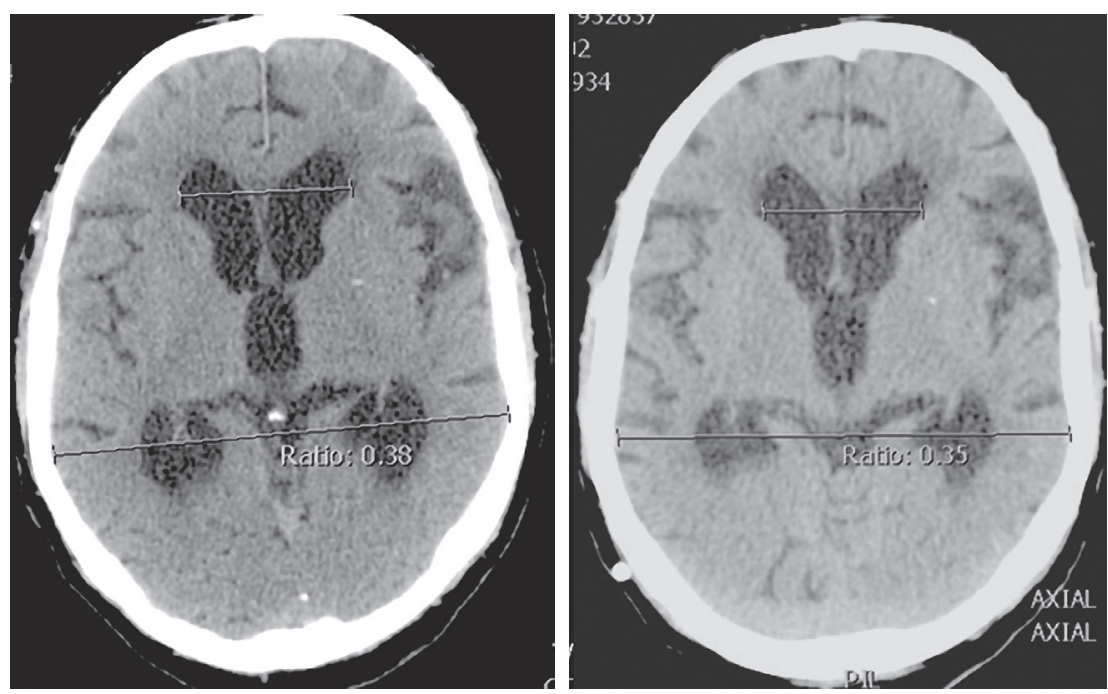

Fig 3. Pre and postoperative skull computed tomography in a typical subject from the sample (patient number 7), with change in Evans Ratio from 0.38 to 0.35 after one year of surgery, related to clinical improvement, especially in gait pattern.
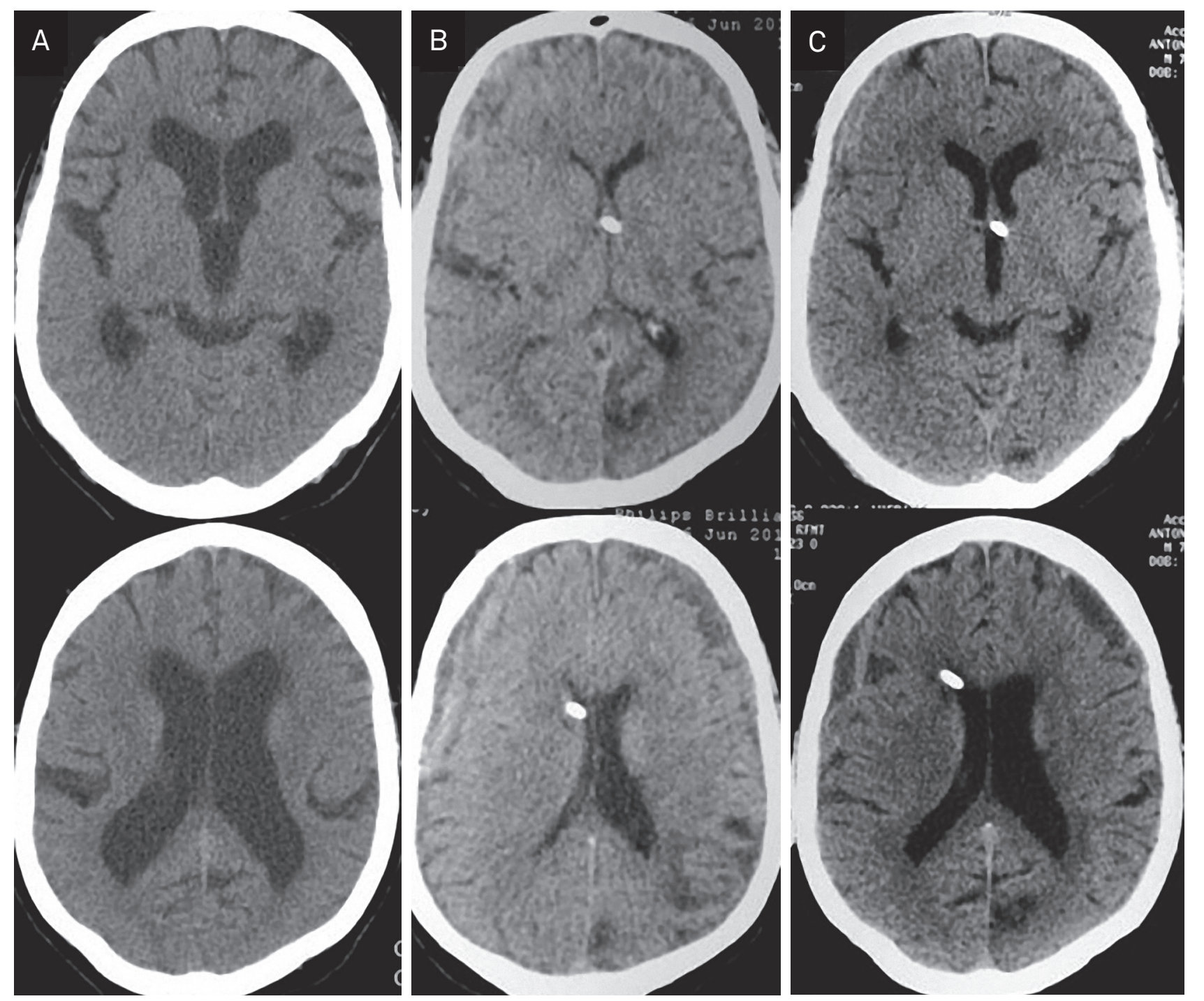

Fig 4. Skull computed tomography of the subject before shunting (column A), in the admission with moderate headache due to bilateral chronic subdural hematomas (column B) and before discharge, with remarkable recovery of sulci and gyri (column C). In this case, due to adjustment of valve pressure, the surgical procedure was not necessary. 
died from subdural empyema) and worsening of profile in one patient. The parameter that showed the best improvement after shunting was the gait, followed by urinary incontinence.

\section{DISCUSSION}

One of the few causes of dementia that is potentially reversible is iNPH. Hakim and Adams described in 1965 the classic triad which can characterize the disease in different degrees of combination ${ }^{3}$.

Diversions with programmable valves are recommended for the treatment of iNPH, since the drainage pressure can be adjusted. Although the programmable valves are widely used, they still lack well-defined protocols to guide the steps to attain proper pressure for each patient ${ }^{20}$.

Other reports on the use of valves are known. The Codman Medos valve allows pressure adjustment in 18 steps between 30 and $200 \mathrm{~mm} \mathrm{H}_{2} \mathrm{O}$. A series of 90 patients was reported with satisfying clinical results ${ }^{23}$. Another retrospective study was published with 583 patients with hydrocephalus due to various causes who were shunted with Codman Hakim programmable valve ${ }^{24}$. The proGAV (Aesculap) valve also has literature support ${ }^{25}$.

The Strata ${ }^{\circledR}$ valve has been described before, including in pediatric patients ${ }^{19,26}$. It has already been stated that adjustments can be used to treat signs or symptoms of cerebrospinal fluid overdrainage or hypodrainage, which may obviate the need for additional surgery. The number of hospital admissions and operations for valve malfunction has decreased ${ }^{27,28}$. Recently, the StrataÒ valve was the object of a study with 72 patients with iNPH, with adequate control of symptoms and long term durability ${ }^{29}$.

The main objective of this study was to reanalyze Strata ${ }^{\circledR}$ performance in a specific protocol for diagnosis and adjustment only in patients with iNPH. The group of patients evaluated in this study was screened for iNPH and 24 showed possibility of improvement with shunting. After shunting, 20 presented objective clinical improvement, measured through tests. According to other reports, approximately $60 \%$ of patients refer improvement after shunting ${ }^{12,13,20,24,29}$. We attribute the better results to the screening design and to the easily adjustable valve to fit each patient's behavior.

Nevertheless, $20.8 \%$ of the patients had complications. Looking at some published statistics of complications, it is possible to see that this percentage varies from 13 to near $40 \%^{12,13,20,22,24,29}$, and we had 5 major complications resulting in surgical interventions.

Nevertheless, the encouraging data are related to the two patients submitted to valve substitution who showed improvement after the surgery. Another confirmed noteworthy aspect was the resolution of the subdural hematomas with no need for surgery, as only valve pressure adjustment was necessary ${ }^{22}$. The absence of shunt infections in our sample can be explained due to the elective characteristic of the surgery, resulting in shorter hospital stay in the pre and post-operative period.

An important concern about Strata ${ }^{\circledR}$ valve use is the potential change in settings after a magnetic resonance examination. It is necessary to follow the patient in order to reset the pressure after such examinations.

Some other questions should be raised. First, when the patient is older, one should be cautious about the results of dementia improvement after shunting. The association with Alzheimer disease and other types of dementia $^{30}$ is known, sometimes with no improvement after shunting.

Unfortunately, we did not apply in this opportunity a multidisciplinary team approach, with the participation of neurologists, geriatricians, physiotherapists, occupational therapists. In addition, we did not apply in this study some known functional scales to evaluate the patients, such as Rankin Scale and Barthel Index. We surely recognize the validity of these tools but we have proposed a protocol based in other objective measurements (MMSE, TUG and JSINPH) and subjective opinion. Moreover, the screening for shunt surgery was based on repeated TT. Neither the Continuous Lumbar Drainage Test nor the Katzman Infusion Test, which are recognized tools used to improve the sensitivity when diagnosing iNPH, were applied to this sample ${ }^{1-3}$. All such observations must be considered and aimed in future projects.

Finally, our results are bound to a one-year follow-up. Although encouraging, they are not yet enough to evaluate a more definitive pattern of response to the Strata $^{\circledR}$ valve.

In conclusion, our results are quite satisfactory as clinical and radiological improvement were observed in $83 \%$ of patients, and the complications, although still frequent (21\%), were easier to be dealt with, because of the capacity of manipulating valve pressure settings.

\section{ACKNOWLEDGEMENTS}

We would like to thank Doctors Jânio Alves Ferreira, Sílvio Tenório Gameleira, Leonardo Takahashi, Luiz Rodrigo Marinho, Arthur Pedro Ribeiro, Rodrigo Cunha and Leonardo Pereira Matias for their cooperation in performing the tasks and follow-up the patients involved in the present study.

We also would like to thank Ms. Sonia Strong for kindly reviewing this manuscript. 
1. Ishikawa M, Hashimoto M, Kuwana N, et al. Guidelines for management of idiopathic normal pressure hydrocephalus. Neurol Med Chir (Tokyo) 2008;48(Suppl):S1-S23.

2. Mori K. Management of idiopathic normal-pressure hydrocephalus: a multiinstitutional study conducted in Japan. J Neurosurg 2001;95:970-973.

3. Shprecher D, Schwalb J, Kurlan R. Normal pressure hydrocephalus: diagnosis and treatment. Curr Neurol Neurosci Rep 2008;8:371-376.

4. Nakayama T, Ouchi Y, Yoshikawa E, Sugihara G, Torizuka T, Tanaka K. Striatal D2 receptor availability after shunting in idiopathic normal pressure hydrocephalus. J Nucl Med 2007;48:1981-1986.

5. Toma AK, Stapleton S, Papadopoulos MC, Kitchen ND, Watkins LD. Natural history of idiopathic normal-pressure hydrocephalus. Neurosurg Rev 2011;34:433-439.

6. Kazui H, Mori E, Hashimoto M, Ishikawa M, Hirono N, Takeda M. Effect of shunt operation on idiopathic normal pressure hydrocephalus patients in reducing caregiver burden: evidence from SINPHONI. Dement Geriatr Cogn Disord 2011;31:363-370.

7. Eide PK, Sorteberg W. Changes in intracranial pulse pressure amplitudes after shunt implantation and adjustment of shunt valve opening pressure in normal pressure hydrocephalus. Acta Neurochir (Wien) 2008;150:1141-1147.

8. Bakker SL, Boon AJ, Wijnhoud AD, Dippel DW, Delwel EJ, Koudstaal PJ. Cerebral hemodynamics before and after shunting in normal pressure hydrocephalus. Acta Neurol Scand 2002;106:123-127.

9. Freimann FB, Streitberger KJ, Klatt D, et al. Alteration of brain viscoelasticity after shunt treatment in normal pressure hydrocephalus. Neuroradiology 2012;54:189-196.

10. Oliveira JRM, Oliveira MF, Kuhni R, Lemos RR, Oliveira DF. Neuro imaging genetics studies in basal ganglia calcification as a model to understand brain resilience. In: The Israel Society for Neuroscience 19th Annual Meeting; 2011.J Mol Neurosc 2011;45(Suppl):S1-S137.

11. Oliveira MF, Pinto FC, Nishikuni K, Botelho RV, Lima AM, Rotta JM. Revisiting hydrocephalus as a model to study brain resilience. Front Hum Neurosci 2011;5:181.

12. McGirt MJ, Woodworth G, Coon AL, Thomas G, Williams MA, Rigamonti D. Diagnosis, treatment, and analysis of long-term outcomes in idiopathic normal-pressure hydrocephalus. Neurosurgery 2008;62(Suppl 2):S670-S677.

13. Zemack G, Romner B. Adjustable valves in normal-pressure hydrocephalus: a retrospective study of 218 patients. Neurosurgery 2002;51:1392-1402.

14. Caruso R, Cervoni L, Vitale AM, Salvati M. Idiopathic normal-pressure hydrocephalus in adults: result of shunting correlated with clinical findings in 18 patients and review of the literature. Neurosurg Rev 1997;20:104-107

15. Larsson A, Wikkelso C, Bilting M, Stephensen H. Clinical parameters in 74 consecutive patients shunt operated for normal pressure hydrocephalus. Acta Neurol Scand 1991;84:475-482.
16. Folstein MF, Robins LN, Helzer JE. The Mini-Mental State Examination Arch Gen Psychiatry 1983;40:812.

17. Feick D, Sickmond J, Liu L, et al. Sensitivity and predictive value of occupational and physical therapy assessments in the functional evaluation of patients with suspected normal pressure hydrocephalus. J Rehabil Med 2008;40:715-720.

18. Kahlon B, Sundbärg G, Rehncrona SJ. Comparison between the lumbar infusion and CSF tap tests to predict outcome after shunt surgery in suspected normal pressure hydrocephalus. J Neurol Neurosurg Psychiatry 2002;73:721-726.

19. Lundkvist B, Eklund A, Koskinen LO, Malm J. An adjustable CSF shunt: advices for clinical use. Acta Neurol Scand 2003;108:38-42.

20. Kim KH, Yeo IS, Yi JS, Lee HJ, Yang JH, Lee IW. A pressure adjustment protocol for programmable valves. J Korean Neurosurg Soc 2009;46:370-377.

21. Inoue T, Kuzu Y, Ogasawara K, Ogawa A. Effect of 3-tesla magnetic resonance imaging on various pressure programmable shunt valves. J Neurosurg 2005;103(Suppl):163-165.

22. Carmel PW, Albright AL, Adelson PD, et al. Incidence and management of subdural hematoma/hygroma with variable- and fixed-pressure differential valves: A randomized, controlled study of programmable compared with conventional valves. Neurosurg Focus 1999;7:7

23. Reinprecht $A$, Czech $T$, Dietrich W. Clinical experience with a new pressure-adjustable shunt valve. Acta Neurochir (Wien) 1995;134:119-124.

24. Zemack G, Romner B. Seven years clinical experience with the Codman Hakim programmable valve: a retrospective study of 583 patients. J Neurosurg 2000;92:941-948.

25. Meier U, Lemcke J. First clinical experiences in patients with idiopathic normal-pressure hydrocephalus with the adjustable gravity valve manufactured by Aesculap (proGAV(Aesculap)). Acta Neurochir 2006;96(Suppl):368-372.

26. Kestle JR, Walker MLJ. A multicenter prospective cohort study of the Strata valve for the management of hydrocephalus in pediatric patients. J Neurosurg 2005;102(Suppl):S141-S145.

27. Kondageski C, Thompson D, Reynolds M, Hayward RD. Experience with the Strata valve in the management of shunt overdrainage. J Neurosurg 2007;106(Suppl 2):S95-S102.

28. Ahn KJ, Koh HS, Kim SH, Youm JY, Song SH, Kim Y. Clinical analysis of programmable valve versus differential pressure valve in hydrocephalus. J Korean Neurosurg Soc 2003;34:230-233.

29. Lundkvist B, Koskinen LO, Birgander R, Eklund A, Malm J. Cerebrospinal fluid dynamics and long-term survival of the Strata valve in idiopathic normal pressure hydrocephalus. Acta Neurol Scand 2011;124:115-121.

30. Hamilton R, Patel S, Lee EB, et al. Lack of shunt response in suspected idiopathic normal pressure hydrocephalus with Alzheimer disease pathology. Ann Neurol 2010;68:535-540. 